\title{
Satisfaction with Life Scale Among Adolescents and Young Adults in Portugal: Extending Evidence of Construct Validity
}

\author{
Ana Daniela Silva • Maria do Céu Taveira • Cátia Marques • \\ Valdiney V. Gouveia
}

Accepted: 16 February 2014

(C) Springer Science+Business Media Dordrecht 2014

\begin{abstract}
The paper presents three empirical studies designed to extend the test of the construct validity of the Satisfaction With Life Scale (SWLS) among Portuguese students. In the first study, the responses of 461 elementary and secondary education students were submitted to a principal component analysis. A solution of one single factor was chosen, accounting for $55.7 \%$ of the total variance, with Cronbach alpha coefficient and inter-item correlation above .70 and .20 , respectively. The second study used a sample of 317 undergraduate students and registered a similar factor solution for SWLS $\left(\phi_{\mathrm{pq}}=0.99\right)$, which accounted for $65.6 \%$ of the total variance (Cronbach alpha .89 and inter-item correlation above .20). A test-retest analysis registered coefficients of .70 (T2) and .77 (T3) and no significant statistically differences between T2, T3 and T1. The third study used a sample of 107 foster care youths from elementary and secondary education. Confirmatory factor analysis results indicate adequate fit indexes for the one-factor solution $\left(\chi^{2} / d f=2.70, \mathrm{GFI}=.96, \mathrm{CFI}=.96\right)$, which showed convergent validity, reliability and homogeneity. In conclusion, there is psychometric evidence for the one-factor structure of the SWLS in Portugal.
\end{abstract}

Keywords Life satisfaction · Well-being · Construct validity · Adolescents · Young adults

A. D. Silva $(\bowtie) \cdot$ M. do Céu Taveira $\cdot$ C. Marques

School of Psychology, University of Minho, Campus of Gualtar, 4710-057 Braga, Portugal e-mail: danielasilva@psi.uminho.pt

M. do Céu Taveira

e-mail: ceuta@psi.uminho.pt

C. Marques

e-mail: catiamarquex@hotmail.com

V. V. Gouveia

Department of Psychology, Federal University of Paraíba, João Pessoa, Brazil

e-mail:vvgouveia@gmail.com 


\section{Introduction}

Life satisfaction (LS) is an important construct for people of all ages, and correlates with many different indicators of mental health. For example, LS has been positively associated with general health, optimism, self-efficacy, and self-esteem (Arrindell et al. 1999; Chmiel et al. 2012; Gadermann et al. 2010; Gilman 2001; Park 2004). Moreover, LS can also be essential for characterizing subjective well-being, and representing its cognitive dimension (Diener et al. 1985). Different instruments have been developed to measure LS (Omery and Dean 2004; Post et al. 2012). One of the most frequently used instruments is the Satisfaction With Life Scale (SWLS; Diener et al. 1985). In fact, studies have emphasized its utility for research purposes (Pavot and Diener 1993; 2008).

One of the reasons for the success of SWLS is that is widely used, and has been translated to over twenty languages worldwide (e.g., Dutch, Taiwanese, Spanish, French, Russian, Korean). Also, SWLS correlates well with different psychological variables and has been the subject of several cross-cultural comparisons (Pavot and Diener 2003). In Portuguese-speaking cultures, the SWLS has been adapted for use in Angola (Sancho et al. 2012), Brazil (Gouveia et al. 2009), and Portugal (Neto et al. 1990). Most of these studies included adults and educated participants (e.g., Laranjeira 2009; Lent et al. 2009; Neto et al. 1990; Sancho et al. 2012; Simões 1992); little or no evidence is available concerning other population groups. When adolescents were considered, only exploratory analyses of the SWLS were performed (Neto 1993, 2001).

This paper presents complementary evidence for the validity and reliability of the Satisfaction With Life Scale (SWLS; Diener et al. 1985) among Portuguese adolescents and young adults. Specifically, three studies were performed to verify the factorial structure, internal consistency, and convergent-discriminant validities of the SWLS. In addition to normal samples, participants in intern regimen, i.e. living in foster care institutions, were also included. We provide evidence for the appropriateness of the SWLS as an indicator of satisfaction with life within diverse Portuguese samples, including youths at risk and people living in foster care institutions. Consequently, the Portuguese version of the SWLS will help researchers and practitioners develop appropriate treatment strategies and riskbased prevention programs, and also help assess the positive aspects of mental health including human well-being (Park 2004).

Some studies of the SWLS support the idea that the scale functions differently in diverse socio-cultural contexts. These studies raise doubts about its appropriateness as a comparative instrument to be used with populations that exhibit different linguistic and/or sociocultural characteristics (Casas et al. 2013). For this reason, we consider it important to explore the use of the scale with different groups of the Portuguese population. These results will be useful to compare with the results obtained by individuals from other countries or sociocultural contexts.

\section{Satisfaction With Life Scale (SWLS)}

The SWLS is a brief self-reported instrument for assessing the cognitive dimension of subjective well-being. Specifically, it is a scale composed of five items that attempt to assess an individual's general sense of satisfaction with their life. The scale uses a 7-point Likert response format (Diener et al. 1985). Evidence for its psychometric adequacy has been reported in several studies: 
Factorial validity. Studies using both exploratory and confirmatory factor analyses have demonstrated that the SWLS only affects a single cognitive dimension (Atienza et al. 2000; Diener et al. 1985; Gouveia et al. 2009; Lewis et al. 1999; Pavot et al. 1991; Sancho et al. 2012). In addition, the factorial structure of the SWLS has been shown to be invariant with respect to gender (Clench-Aas et al. 2011; Wu and Yao 2006) and age (Glaesmer et al. 2011; Pons et al. 2000).

Criterion-related validity. In agreement with theory, scores on the SWLS have been correlated with affective and psychological distress. Specifically, higher scores in SWLS have been associated with high positive and low negative affective distress (Schimmack 2003; Vera-Villarroel et al. 2012), and have been negatively correlated with anxiety, depression, and general psychological distress (Arrindell et al. 1991; Kim et al. 2013). Similar findings were observed with five Brazilian samples where SWLS scores positively related to positive affect $(r=0.62)$ and negatively related to both negative affect and psychological distress ( $r=-0.21$ and -0.51 , respectively; Gouveia et al. 2009).

Reliability. Test-retests reliabilities have ranged from .83 (2 weeks) to .54 (4 years), and coefficients alpha have ranged from .79 to .89 (Pavot and Diener 1993; Pavot et al. 1991). Regarding Cronbach's alpha, similar findings were observed by Gouveia et al. (2009). They reported alphas from .77 (students, general population) to .88 (physicians). These findings coincide with other results in the literature presenting coefficients between .70 and .90 (Laranjeira 2009; Neto 1993, 2001; Neto et al. 1990; Simões 1992) and greater than 90 (Lent et al. 2009; Sancho et al. 2012). Reinforcing this psychometric parameter, evidence for its homogeneity (mean of inter-item correlation) registered values between .40 and 60 (Gouveia et al. 2009; Neto 1993, 2001).

The SWLS has exhibited empirical evidence for its validity and reliability in many cultural contexts, including in Portugal (Lent et al. 2009; Neto 1993, 2001; Neto et al. 1990; Simões 1992). Nevertheless, the studies developed in this cultural context have focused on exploratory analysis of the SWLS psychometric properties with specific groups (e.g., institutionalized elderlies, teachers, undergraduate students). Therefore, it is necessary to enlarge the study of the Portuguese version of SWLS by performing more robust statistical analyses, supporting evidences of validity and reliability, and including the participation of other population groups.

\section{Current Studies}

Previous studies have explored the psychometric properties of the Portuguese version of the SWLS (e.g., Lent et al. 2009; Sancho et al. 2012). In general, all studies suggest the appropriateness of the psychometric proprieties of this scale by presenting a one-factor solution and acceptable reliability coefficients. However, there has been no systematic interest to replicate and extend these results, for example, by performing exploratory and confirmatory analysis. The next three studies aim to contribute to this objective.

\subsection{Study 1. Construct Validity of the SWLS with Adolescents Living with their Families}

This study aimed to offer the first evidence of construct validity of the $S W L S$ considering a sample of adolescents living with their families. We expect SWLS to be an adequate measure of LS for use with youths in Portugal. We, therefore, expect to identify a onedimensional structural model of LS with this instrument. 


\subsubsection{Method}

3.1.1.1 Participants Participants included 461 adolescent students from the northern $(n=393)$ mainland and islands $(n=68)$ of Portugal. Most participants were female $(55.1 \%)$, with mean participant age ranging from 13 to 21 years $(m=16.9, s d=1.67)$, and were attending elementary $(n=52)$ or high schools $(n=409)$. This was a convenience sample, i.e., subjects were those who were present in class on the day of data collection and who agreed to participate in the research.

3.1.1.2 Instrument Participants answered the Portuguese version of the Satisfaction with Life Scale (SWLS; Neto 1990) as well as a number of demographic questions (e.g., age, sex, school degree). The SWLS included five items (e.g., I am satisfied with my life; So far I have gotten the important things I want in life). The SWLS was rated with a 7-point scale, ranging from 1 (strongly disagree) to 7 (strongly agree).

3.1.1.3 Procedure All participants sat collectively in a classroom to answer the instruments. However, all responses were given individually. Researchers informed the participants that their participation was voluntary. On average, 10 min were sufficient to finish the instrument.

\subsubsection{Results}

To accomplish the aim of this study, we first analyzed the factorial structure of the SWLS $\left[K M O=0.82\right.$ and $\left.\chi^{2}(10)=646.28, p<.001\right]$ using principal component analysis. We used the criterion of eigenvalue greater than 1 to define the number of factors to retain. In this condition, only one factor emerged (eigenvalue $=2.79$ ) and accounted for $55.7 \%$ of the total variance (Table 1). The factorial loads ranged from .69 (Item 3. I am satisfied with my life) to .80 (Item 1. In most ways my life is close to my ideal) (Table 2).

We also checked the reliability of the SWLS. Specifically, Cronbach's alpha was calculated to be .80 . The homogeneity, i.e. mean inter-item correlation, was 0.45 . The lowest and highest coefficients corresponded to .36 (Items 2 and 5) and .53 (Items 4 and 5), respectively.

\subsubsection{Partial Discussion}

The current study is the first complementary evidence of construct validity of the SWLS in Portugal using an adolescent sample. In agreement with previous studies, this instrument showed a one-factor structure, and was shown to be reliable with Cronbach's alpha and the inter-item correlation above the cut-off of .70 and .20 , respectively. These results support its construct validity.

\subsection{Study 2. Construct Validity of the SWLS with Undergraduate Students}

The current study aimed to replicate Study 1. In this case, Study 2 included undergraduate students taking their first year of technological and humanity courses. We checked SWLS factorial structure and reliability (intern consistency, inter-item correlation, and temporal stability). The resulting Cronbach's alpha and factorial structure were compared with those on Study 1 in order to test the congruence of this scale. 
Table 1 Descriptive statistics for the five items of the SWLS in adolescent student samples

\begin{tabular}{lllllllll}
\hline Item content & $m(s d)$ & 1 & 2 & 3 & 4 & 5 & $m(s d)$ \\
\hline 1. In most ways my life is close to my ideal & $4.7(1.37)$ & & $.54^{*}$ & $.63^{*}$ & $.57^{*}$ & $.53^{*}$ & $4.5(1.23)$ \\
2. The conditions of my life are excellent & $5.2(1.36)$ & $.48^{*}$ & & $.67^{*}$ & $.46^{*}$ & $.43^{*}$ & $4.6(1.34)$ \\
3. I am satisfied with my life & $5.3(1.87)$ & $.44^{*}$ & $.44^{*}$ & & $.65^{*}$ & $.60^{*}$ & $5.1(1.24)$ \\
$\begin{array}{l}\text { 4. So far I have gotten the important things I want } \\
\text { in life }\end{array}$ & $4.9(1.37)$ & $.51^{*}$ & $.44^{*}$ & $.38^{*}$ & & $.59^{*}$ & $5.0(1.28)$ \\
$\begin{array}{l}\text { 5. If I could live my life over, I would change } \\
\text { almost nothing }\end{array}$ & $4.2(1.88)$ & $.52^{*}$ & $.36^{*}$ & $.38^{*}$ & $.53^{*}$ & & $4.3(1.74)$ \\
\hline
\end{tabular}

Note Responses were made on a 7-point scale, ranging from 1 (strongly disagree) to 7 (strongly agree). Correlations below the diagonal correspond to Study 1, and above correspond to Study 2

* indicate $p<.05$

\subsubsection{Method}

3.2.1.1 Participants A total of 317 participants were included in this study. They were first year undergraduate students enrolled in Psychology/Education $(n=104)$ or Engineering $(n=213)$ courses in Minho and Porto universities (Portugal). Most participants were male $(56.2 \%)$ with a mean age of $19.8(s d=1.03)$ years. This was a convenience sample, i.e., nonrandom. All participants present in class were invited to voluntarily collaborate in the first phase $\left(T_{1}\right)$. Some were also considered for a second phase ten $\left(T_{2}\right.$; $n=156)$ and nineteen $\left(T_{3} ; n=48\right)$ weeks later. These measurement times were based on our practical experiences in Portuguese universities. During the first week the students are more relaxed, enjoying the academic climate, maintaining contact with their colleagues and teachers. However, during the fifth and seventh weeks, when the exams are close, it is evident a stressful context among the students, which can affect their scores on well-being measures, such as life satisfaction. Hence, we waited to finish the impact of the first exams, concentrating the data collection in more tranquil and stable moments.

3.2.1.2 Instrument and Procedure Participants answered the same questionnaire as in Study 1. Firstly, they considered the Portuguese version of the SWLS and then demographic questions. The data collection was performed in a collective class context, but the participation was individual.

\subsubsection{Results}

As in Study 1, we performed a principal component analysis $\left[K M O=0.84\right.$ and $\chi^{2}$ $(10)=744.31, p<.001]$ without fixing any criterion, i.e., number of factors to retain or rotation method. According to this analysis, only one factor has emerged (eigenvalue of 3.28), and accounted for $65.6 \%$ of the total variance (Table 1). This general factor, named as life satisfaction, included the scale's five items with item factorial loadings ranging from .76 (Item 2. The conditions of my life are excellent) to .89 (Item 3. I am satisfied with my life). This structure was congruent with that of Study $1\left(\phi_{\mathrm{pq}}=0.99\right)($ Table 2$)$.

Several reliability coefficients were calculated. The Cronbach's alpha for the SWLS was 0.86 . This was shown to be no different from Study $1\left(W_{\text {statistic }}=1.29, p>.05\right)$. The homogeneity (mean inter-item correlation) was 0.57 , and ranged from .43 (Items 2 and 5) to .67 (Items 2 and 3). Finally, the temporal stability (test-retest) was tested. Coefficients 
of .70 $\left(T_{2}\right)$ and $.77\left(T_{3}\right)$ were observed. No statistical significant differences were observed between scores of $T_{2}$ and $T_{3}$ with respect to $T_{1}$ ( $t<1$ for both).

\subsubsection{Partial Discussion}

The results of Study 2 suggest the adequacy of the SWLS by corroborating findings from Study 1. Even considering a different sample, evidence for a one-factor structure was observed in this new and different sample. These results replicated those reported in previous studies (Bedeian et al. 1988). Results also indicated coherent reliability coefficients, including temporal stability. Despite this, we have only studied participants in conventional contexts, i.e., students of different school degrees commonly living with their parents. Furthermore, our statistical analyses were essentially exploratory. These considerations motivated us to perform a third study).

\subsection{Study 3. Construct Validity of the SWLS in Foster Care Youths}

This study aimed to test the one-factor solution for a different sample of participants. A confirmatory factor analysis was performed. To aggregate evidences of construct validity, we also calculated the convergent validity (average variance extracted, AVE) and indicators of reliability [Cronbach's alpha, inter-item correlations, and composite reliability (CR; Hair et al. 2006)].

\subsubsection{Method}

3.3.1.1 Participants Participants in this study included 107 adolescents in northern $(n=63)$, central $(n=26)$ areas and islands $(n=18)$ of Portugal. All participants were in intern regimen, i.e. living in foster care institutions. The participants were mostly men $(53.3 \%)$ with a mean age of $16.4(s d=1.96)$ years ranging from 12 to 21 years old.

3.3.1.2 Instrument and Procedure Participants answered the Portuguese version of the SWLS and demographic questions, in this order. Data collection was performed in groups of 5-10 participants in a specific room designated for this activity. Despite this collective context, the participation was individual. A research collaborator was present in the room, and helped participants complete the task.

\subsubsection{Results}

A confirmatory factor analysis was performed, and demonstrated the one-factor structure observed from studies 1 and 2 . The covariance matrix was used as input, and assumed the maximum likelihood estimator. Values of $\chi^{2} / d f$ ranged from 2 to 5, GFI and CFI were.90 or above, RMSEA was close to .10 or below, and Pclose was greater than .05. These results suggested that adequate fit indexes were obtained (Byrne 2010). The chosen solution is presented in Fig. 1.

The SWLS structure obtained the following fit indexes: $\chi^{2} / d f=2.70$; GFI $=.96$; $\mathrm{CFI}=.96 ;$ RMSEA $=.126(90 \% \mathrm{IC}=.047-.210)$; and Pclose $=.056$. Using the standardized regression weights in Table 3, we calculated the corresponding AVE (.51) and $C R$ (.84). Finally, we analyzed the homogeneity $\left[r_{i . i .}=.50\right.$; ranging from .40 (Items 2 and 4 ) to .64 (Items 3 and 5)] and calculated Cronbach's alpha (0.83). Cronbach's alpha was not 
Table 2 Factorial structure of the satisfaction with life scale (SWLS)

\begin{tabular}{lcr}
\hline Item content & Factorial loadings \\
\cline { 2 - 3 } & Study 1 & Study 2 \\
\hline 1. In most ways my life is close to my idea. & 0.80 & 0.81 \\
4. So far I have gotten the important things I want in life & 0.77 & 0.76 \\
5. If I could live my life over, I would change almost nothing & 0.75 & 0.89 \\
2. The conditions of my life are excellent & 0.72 & 0.81 \\
3. I am satisfied with my life & 0.69 & 0.76 \\
Eigenvalue & 2.79 & 3.28 \\
\% Total variance & 55.7 & 65.6 \\
Cronbach's alpha & 0.80 & 0.86 \\
Homogeneity $\left(r_{i . i}\right)$ & 0.45 & 0.57 \\
\hline
\end{tabular}

Fig. 1 Factorial structure and loadings of the satisfaction with life scale (SWLS)

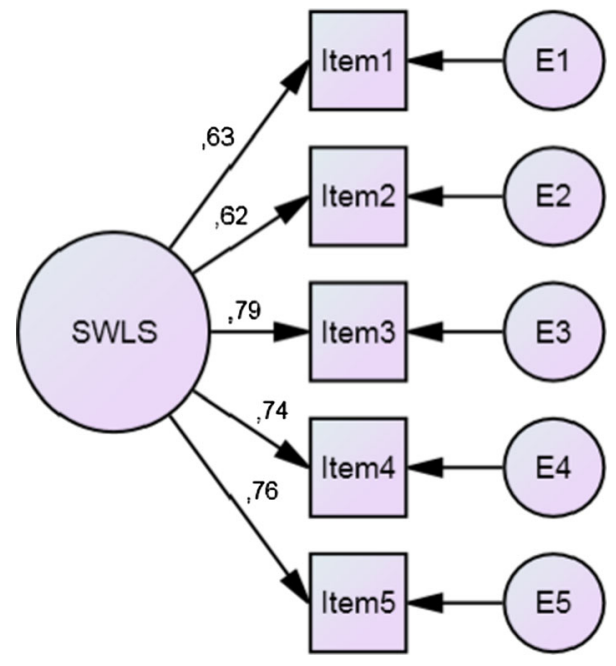

different from those of Study $1\left(W_{\text {statistic }}=1.06, p>.05\right)$ or Study $2\left(W_{\text {statistic }}=0.82\right.$, $p>.05)$.

\subsubsection{Partial Discussion}

According to the obtained results, all fit indexes were adequate except for RMSEA. However, the Pclose permits not to discard the hypothesis because this indicator is equal or $<0.05$. So, it seems the one-factor structure of the $S W L S$ in Portugal is evident. Findings of convergent validity (AVE) support this conclusion (Hair et al. 2006). Moreover, Cronbach's alpha was adequate (Nunnally and Bernstein 1994) and similar to that of previous reported studies. The SWLS homogeneity also meets the recommended criterion, including the $C R$ (Škerlavaj and Dimovski 2009). 
Table 3 Descriptive statistics for the five items of the SWLS in interned adolescent sample

\begin{tabular}{lllllll}
\hline Item content & $m(s d)$ & $\lambda$ & 1 & 2 & 3 & 4 \\
\hline 1. In most ways my life is close to my ideal & $4.4(1.69)$ & .63 & & & \\
2. The conditions of my life are excellent & $4.7(1.60)$ & .63 & $.44^{*}$ & & \\
3. I am satisfied with my life & $4.8(1.71)$ & .79 & $.41^{*}$ & $.53^{*}$ & \\
4. So far I have gotten the important things I want in life & $4.6(1.81)$ & .74 & $.58^{*}$ & $.40^{*}$ & $.58^{*}$ & \\
5. If I could live my life over, I would change almost nothing & $3.6(2.13)$ & .76 & $.46^{*}$ & $.47^{*}$ & $.64^{*}$ & $.53^{*}$
\end{tabular}

Note Responses were made on a 7-point scale, ranging from 1 (strongly disagree) to 7 (strongly agree). $\lambda=$ Standardized regression weights

$*$ indicate $p<.05$

\section{General Discussion}

Since its elaboration in the 1980s, the SWLS has been one of most used measures to capture the cognitive-judgmental dimension of subjective well-being. Some studies have analyzed psychometric parameters within a Portuguese context, however, they used exploratory analyses with mainly adults subjects. In contrast, this article considered adolescents and young adults (ages ranging from 12 to 21 years) with different cultural backgrounds including youths living with their family, undergraduate students, and youths living in foster care institutions. Moreover, in addition to exploratory analyses we also performed confirmatory factor analysis, and offered additional evidence for the temporal stability and convergent validity of the SWLS.

Overall, our results supported those published previously. Consistently, the SWLS was identified with a general factor of life satisfaction; this was congruent for studies 1 and 2 . This factor showed factorial loading ranging from 0.69 (Item 3. I am satisfied with my life; Study 1) to 0.89 (Item 5. If I could live my life over, I would change almost nothing; Study 2 ), and therefore corroborated previous studies with the Portuguese version of this measure (Gouveia et al. 2009; Neto 2001). These findings were also corroborated in Study 3. Results coincided with results described by other authors (Glaesmer et al. 2011; Sancho et al. 2012) using confirmatory factor analysis with non-Portuguese samples. The fit indexes were acceptable according to recommended cutoffs (Byrne 2010; Hair et al. 2006). The only exception was RMSEA, which did not meet the recommended cutoffs. However, the corresponding Pclose seemed to support that the coefficient was admissible.

Evidence of reliability was also demonstrated. The SWLS showed Cronbach's alpha (Nunnally and Bernstein 1994) and composite reliability (Škerlavaj and Dimovski 2009) values higher than the recommended cutoff (0.70). The mean correlation of its item with each other was above of 0.40, which is assessed as excellent (Clark and Watson 1995). Moreover, the temporal stability coefficients were close to those observed in other studies with values at least 0.70 in the period of 10 weeks (Pavot et al. 1991; Pavot and Diener 1993).

Finally, the present findings reinforce the psychometric appropriateness of the factorial structure and reliability of the SWLS. The results based on exploratory and confirmatory factor analyses corroborate the one-factor structure of the SWLS (Atienza et al. 2000; Gouveia et al. 2009; Neto 2001; Sancho et al. 2012), and demonstrated acceptable reliability. Therefore, the SWLS is a scale useful to measure the cognitive-judgmental 
component of subjective well-being. Researchers can therefore adequately use the SWLS to study life satisfaction among adolescents and young adults in Portugal.

It is important consider some limitations of the results presented in order to suggest potential future research in this domain. One of these limitations is the larger amplitude of ages in the samples studied. It is explained by the objectives of two larger projects in which the studies of well-being presented fall: a study of career development and wellbeing of foster youth and a study of academic adjustment of college students. The objective of the present study was to test the psychometric properties of the SWLS in youths with different ages. However, new studies with larger samples should be designed to analyze the factor structure of SWLS across different age and gender groups. The analysis of the relationships between the SWLS and different demographic variables would enhance the meaningfulness of the findings and greatly improve this research.

\section{References}

Arrindell, W. A., Meeuwesen, L., \& Huyse, F. J. (1991). The satisfaction with life scale (SWLS): Psychometric properties in a non-psychiatric medical outpatients sample. Personality and Individual Differences, 12, 117-123.

Arrindell, W. A., Heesink, J., \& Feij, J. A. (1999). The satisfaction with life scale (SWLS): Appraisal with 1700 healthy young adults in The Netherlands. Personality and Individual Differences, 26, 815-826.

Atienza, F. L., Pons, D., Balaguer, I., \& García-Merita, M. (2000). Propiedades psicométricas de la Escala de Satisfacción con la Vida en adolescentes. Psicothema, 12, 314-319.

Bedeian, A. G., Armenakis, A. A., \& Randolph, W. A. (1988). The significance of congruence coefficients: A comment and statistical test. Journal of Management, 14, 559-566.

Byrne, B. M. (2010). Structural equation modeling with Amos: Basic concepts, applications, and programmimg ( $2^{\mathrm{a}}$ ed.). New York: Routledge.

Casas, F., Fernández-Artamendi, S., Montserrat, C., Bravo, A., Bertrán, I., \& Valle, J. (2013). El bienestar subjetivo en la adolescencia: Estudio comparativo de dos Comunidades Autónomas en España. Anales de psicología, 29(1), 148-158.

Chmiel, M., Brunner, M., Martin, R., \& Schalke, D. (2012). Revisiting the structure of subjective well-being in middle-aged adults. Social Indicators Research, 106, 109-116.

Clark, L. A., \& Watson, D. (1995). Constructing validity: Basic issues in objective scale development. Psychological Assessment, 7, 309-319.

Clench-Aas, J., Nes, R. B., Dalgard, O. S., \& Aaro, L. E. (2011). Dimensionality and measurement invariance in the satisfaction with life scale in Norway. Quality of Life Research, 20, 1307-1317.

Diener, E., Emmons, R. A., Larsen, R. J., \& Griffin, S. (1985). The satisfaction with life scale. Journal of Personality Assessment, 49, 71-75.

Gadermann, A. M., Schonert-Reichl, K. A., \& Zumbo, B. D. (2010). Investigating validity evidence of the satisfaction with life scale adapted for children. Social Indicators Research, 96, 229-247.

Gilman, R. (2001). The relationship between life satisfaction, social interest, and frequency of extracurricular activities among adolescent students. Journal of Youth and Adolescence, 30, 749-767.

Glaesmer, H., Grande, G., Braehler, E., \& Roth, M. (2011). The German version of the Satisfaction with Life Scale (SWLS): Psychometric properties, validity, and population-based norms. European Journal of Psychological Assessment, 27, 127-132.

Gouveia, V. V., Milfont, T. L., Fonseca, P. N., \& Coelho, J. A. (2009). Life satisfaction in Brazil: Testing the psychometric properties of the satisfaction with life scale (SWLS) in five Brazilian samples. Social Indicators Research, 90, 267-277.

Hair, J. F., Jr, Black, W. C., Babin, B. J., Anderson, R. E., \& Tatham, R. L. (2006). Multivariate data analysis ( $6^{\mathrm{a}}$ ed.). Upper Saddle River, NJ: Pearson Prentice Hall.

Kim, J. W., Han, D. H., Lee, Y. S., Min, K. J., Park, J. Y., \& Lee, K. (2013). The effect of depression, anxiety, self-esteem, temperament, and character on life satisfaction in college students. Journal of Korean Neuropsychiatry Association, 52, 150-156.

Laranjeira, C. A. (2009). Preliminary validation study of the Portuguese version of the satisfaction with life scale. Psychology, Health \& Medicine, 14, 220-226. 
Lent, R. W., Taveira, M. C., Sheu, H. B., \& Singley, D. (2009). Social cognitive predictors of academic adjustment and life satisfaction in Portuguese college students: A longitudinal analysis. Journal of Vocational Behavior, 74, 190-198.

Lewis, C. A., Shevlin, M. E., Smekal, V., \& Dorahy, M. J. (1999). Factor structure and reliability of a Czech translation of the Satisfaction With Life Scale among Czech university students. Studia Psychologica, 41, 239-244.

Neto, F. (1990). Satisfação com a vida e características de personalidade. Psychologica, 22, 55-70.

Neto, F. (1993). The Satisfaction With Life Scale: Psychometrics properties in an adolescent sample. Journal of Youth and Adolescence, 22, 125-134.

Neto, F. (2001). Satisfaction with life among adolescents from immigrant families in Portugal. Journal of Youth and Adolescence, 30, 53-67.

Neto, F., Barros, J., \& Barros, A. (1990). Satisfação com a vida [Satisfaction with life]. In L. Almeida, R. Santiago, P. Silva, L. Oliveira, O. Caetano, J. Marques, \& J. Marques (Eds.), A acção educativa: Análise psico-social (pp. 91-100). Leiria, Portugal: ESEL/APPORT.

Nunnally, J. C., \& Bernstein, I. H. (1994). Psychometric theory (3rd ed.). New York: McGraw-Hill.

Omery, A. K., \& Dean, H. (2004). Multiple instruments for measuring quality of life. In M. FrankStromborg \& S. J. Olsen (Eds.), Instruments for clinical health-care research (pp. 150-163). Sudbury, MA: Jones \& Bartlett Publishers.

Park, N. (2004). The role of subjective well-being in positive youth development. The ANNALS of the American Academy of Political and Social Science, 591, 25-39.

Pavot, W., \& Diener, E. (1993). Review of the Satisfaction With Life Scale. Psychological Assessment, 5 , 164-172.

Pavot, W., \& Diener, E. (2003). Well-being (including life satisfaction). In R. Fernández-Ballesteros (Ed.), Encyclopedia of psychological assessment (pp. 1097-1101). London: Sage Publications.

Pavot, W., \& Diener, E. (2008). The Satisfaction With Life Scale and the emerging construct of life satisfaction. Journal of Positive Psychology, 3, 137-152.

Pavot, W., Diener, E., Colvin, C. R., \& Sandvik, E. (1991). Further validation of the Satisfaction With Life Scale: Evidence for the cross-method convergence of well-being measures. Journal of Personality Assessment, 57, 149-161.

Pons, D., Atienza, F. L., Balaquer, I., \& García-Merita, M. L. (2000). Satisfaction with life scale: Analysis of factorial invariance for adolescents and elderly. Perceptual and Motor Skills, 91, 62-68.

Post, M. W., van Leeuwen, C. M., van Koppenhagen, C. F., \& de Groot, S. (2012). Validity of the life satisfaction questions, the life satisfaction questionnaire, and the satisfaction with life scale in persons with spinal cord injury. Archives of Physical Medicine and Rehabilitation, 93, 1832-1837.

Sancho, P., Galiana, L., Gutierrez, M., Francisco, E., \& Tomás, J. M. (2012). Validating the Portuguese version of the Satisfaction With Life Scale in an elderly sample. Social Indicators Research. Retrieved on September, 30th, 2012: http://link.springer.com/article/10.1007/s11205-012-9994-y.

Schimmack, U. (2003). Affect measurement in experience sampling research. Journal of Happiness Studies, 4, 79-106.

Simões, A. (1992). Ulterior validação de uma escala de satisfação com a vida (SWLS). Revista Portuguesa de Pedagogia, 3, 503-515.

Škerlavaj, M., \& Dimovski, V. (2009). Organizational learning and performance in two national cultures: A multi-group structural equation modeling approach. In W. R. King (Ed.), Knowledge management and organizational learning (Vol. 4, pp. 321-366). New York: Springer.

Vera-Villarroel, P., Urzúa, A. M., Pavez, P., Celis-Atenas, K., \& Silva, J. (2012). Evaluation of subjective well-being: Analysis of the Satisfaction with Life Scale in Chilean Population. Universitas Psychologica, 11, 719-727.

Wu, C., \& Yao, G. (2006). Analysis of factorial invariance across gender in the Taiwan version of the Satisfaction with Life Scale. Personality and Individual Differences, 40, 1259-1268. 